\title{
REGIONAL POLICY OF THE EUROPEAN UNION AS A MEANS OF THE CONSOLIDATION OF THE SMART CITIES AND REGIONAL PLANNING
}

DOI: http://dx.doi.org/10.18509/GBP.2019.65

UDC: 711.433:711.2-043.86(4-672EУ)

\author{
Metodi Ivanov \\ Sofia University „St. Kliment Ohridski“, Faculty of Geology and Geography, \\ Department "Regional Development", Sofia, Bulgaria
}

\begin{abstract}
Creating opportunities for the development of cities and regions in the European Union goes through the structuring and building of a regional policy that combines intelligent urban and regional planning, leading to an increase in economic growth in the regions and the quality of life by planning strategic investments in underdeveloped regions to reach the levels of socio-economic development of the leading regions of the European Union. This study aims to investigate and analyze the specifics, practices, normative and methodological prerequisites and limitations in the formation of effective regional policy as a means of achieving balanced economic growth based on the policy of building smart cities of the future. This process requires a review of the development of regional planning and its impact on smart urban development. In addition, the key models for smart urban development should be identified by exploring good practices, and this requires research and critical analysis of regulatory and strategic documents relating to regional policy in the European Union. The development of regional policy in the European Union should focus not only on a limited number of key investment priorities, but also on the objectives, the resources available and the resources needed to measure the progress of individual regions and smart cities of the future.
\end{abstract}

Keywords: smart cities, regional planning, regional development, socio-economic development, spatial planning

\section{INTRODUCTION}

Creating opportunities for urban and regional development in the European Union goes through the discussion of cohesion issues, which provide an opportunity to discuss the shape of the future cohesion policy, which also goes through the implementation of a simplified, timely and cost-effective regional policy that encourages more reforms in the Member States in the European Union. In order to increase regional economic growth and quality of life, it is necessary, in addition to planning strategic investments in underdeveloped regions, to seek more incentives and to pursue a policy of reducing sanctions. One of the main tasks facing modern regional policy is to create opportunities for all European citizens in the coming decades, regardless of where they live, to have equal opportunities and at the same time to be given concrete benefits by the European Union, which is complemented by its concept of a strategic investment policy that should cover all regions and cities in the European Union in order to promote regional economic growth and improve the quality of life of citizens in the different regions. The development of smart cities and the convergence in the development of the regions also goes through the examination of the macro-regional strategy at European Union level, which outlines the political framework in which the countries located in the same region 
find solutions to the problems that have arisen, while at the same time using the common your potential to solve the current problems they face. By using a strategic approach, cooperation can be strengthened and new effective policies based on the establishment of an appropriate partnership can be developed, while creating an adequate mechanism for enhancing cooperation between the regions. Naturally, due attention should also be paid to improving the coordination of actions with regard to relevant regional policies and their sources of funding, and an important place in this process is the implementation of integrated development strategies for the regions that will have an impact on the development of smart cities. This requires increasing investment in innovation, improving infrastructure development in the regions, creating opportunities for attracting highly qualified labor to prospective cities for smart cities. At the same time, there must be a process of creating the increasingly attractive conditions for business development in lagging regions, which requires the implementation of regional policies to connect businesses, research centers and specialized business services in all regions in order to achieve a regional smart economic growth.

The concentration of consumers, workers and businesses in a place or area, together with the formal and informal institutions that are found in cities, makes urban areas more than just centres of population. They are the centres of activity of all kinds, and in particular economic activity. Sixty-seven per cent of Europe's GDP is generated in metropolitan regions, while their population represents only fifty-nine per cent of the total European population. A comparison of European cities' economic performance indicates that the major cities are doing better than the rest, [1] and capitals and larger metropolitan regions have performed better during the economic crisis than smaller metropolitan and nonmetropolitan regions [2]. Small and medium-sized cities, however, form the backbone of Europe's territory and have an important role to play for territorial development and cohesion. [3]

\section{IN INFLUENCE OF STRATEGIC SPATIAL PLANNING AS AN OPPORTUNITY FOR THE DEVELOPMENT OF SMART CITIES AND REGIONS IN THE EUROPEAN UNION}

The development of an effective regional policy aimed at the development of smart cities goes through the use of strategic spatial planning as an opportunity to implement a policy of convergence of the regions and overcoming their differences. The use of strategic spatial planning presupposes the systematization of the main features of strategic spatial planning, for which we will first have to identify and measure the individual spaces that are being planned. Under a functional urban area, we must understand "a distinct geographic space suitable for comparison between the economic development of individual urban territories" [4]. This distinctive space is characterized by the possibility for businesses to have a wide range of built-in infrastructure and services such as telecommunication services, retail outlets and skilled labor, as well as educational institutions and research centers. Or, with regard to business entities under a functional urban area, a distinctive space must be understood in which economic entities can function effectively. Here is where we should also mention the objectives of spatial planning, namely to promote territorial cohesion through more balanced economic and social development of the regions, as well as improving the competitiveness of individual territorial units. At the same time, it is necessary to encourage the development and improvement of the relationship between town and country by promoting a more balanced accessibility and access to information and knowledge as well as reducing environmental 
damage as a result of anthropogenic action. In addition, spatial planning should also aim at improving and preserving natural resources and natural heritage, improving cultural heritage, developing energy resources, promoting the development of high-quality, sustainable tourism. In a UN report of 2008. spatial planning is defined as a "public sector function that affects the spatial distribution of activities and aims at creating a rational territorial organization of the use of natural resources and links to achieve balanced development and environmental protection and achieving specific social and economic objectives "[5]. Spatial planning involves the introduction of measures to coordinate and improve the geographical impacts of identified sectoral policies, which seeks to achieve a balanced distribution of economic development within a given territory, and therefore we can regard spatial planning as an important lever to promote sustainable development and the search for opportunities to improve the quality of life of the population in individual populated areas. Regarding the development of the territory and the formation of specific local and national policies, we can consider spatial planning simultaneously as a mechanism for regulating and developing the space / territory. In this connection, from the point of view of the public sector, mechanisms are created for the enforcement of regulations by the central government, both at local and regional level, when approving certain activities through planning for territorial development. Spatial planning, on the other hand, is also a development mechanism, as central and local authorities have to develop and develop tools for the development of the territory in order to create the opportunity to provide more services to businesses and the population, new and the renewal of existing infrastructure, the creation of guidelines for the development of the urban environment, the protection of national resources and, last but not least, the creation of incentives for business investment expanding production activities and hiring a workforce.

One of the main objectives of spatial planning and the definition of regional development policy for the individual region should be to promote innovation, knowledge and research. Particular importance for the development and construction of a spatial model will be where the efforts of the administrative structures are aimed at promoting investment in intangible assets and human capital in order to maximize efficiency in the use and deployment of new and existing technologies in space modeling. In this respect, outside the boundaries of regional policy-making, support for entrepreneurship and the development of industrial sectors comes about, which can be achieved through specific actions and measures in education policies, the development of the internal market, improvement of the financial services offered and tax relief politics. The need for effective spatial planning is one of the main reasons for avoiding duplication of efforts and actions on the part of ministries, trade companies, municipalities and private individuals. Characterizing spatial planning as a public sector activity that takes place at all levels of governance, we must undoubtedly look at the cross-sectoral nature of spatial planning and its importance for the development of the territory. As at the national level, the responsibility for the development of framework policies lies with the government of the country that initiates and guides the overall decision-making process, as well as the creation of conditions for exploitation and the implementation of effective planning at regional and local level. Here, we should also note the main tasks at the national level, namely the creation of an effective framework, legislation, coordination with other sectors and between regions, monitoring the implementation of national guidelines and principles at regional and local level as well as identification of problems in the implementation of spatial planning and implementation of regional development plans of 
individual territorial units. It is the responsibility of national (central) authorities to assist regional authorities in implementing the defined national development guidelines by building capacity in terms of professional experience and political leadership.

\section{REGIONAL PLANNING AND ITS IMPACT ON SMART URBAN DEVELOPMENT.}

The concept of achieving smart urban development over recent years has had a strong impact on the upgrading of urban strategies in both large and small cities. The common understanding of the concept of a "smart city" is based on the development and implementation of a regional strategy that incorporates modern factors of urban production into a common framework that pays particular attention to information and communication technologies as a means of permanently resolving growing problems in urban areas. The need to cope with rising urban problems obliges local authorities, regional companies, non-profit organizations and the citizens themselves to adopt the concept and development of the idea of a smart city that creates better living conditions and protection of the environment through the use of information and communication technologies.

This society's drive to achieve smart urban development is clearly seen in the development of public government decisions and the development of projects to develop cities as smart. An important place in the definition of regional development policy for cities and regions is the specific definition of the concept of a smart city that includes all aspects of urban life, starting with the development of modern forms of tourism and trade and the improvement of industrial production and the upgrading of agriculture have led to the building of modern logistic relations. The development of a smart city program affects the appearance of all urban infrastructures, starting from public and private buildings, and modernizing factories and transport facilities. The planning and development of smart cities requires the use of a strong information and communication infrastructure that should support knowledge management in the urban context and ensure the sustainability of cities' development. Too much relies on the use of modern technologies to improve the quality of life in urban areas and to reduce pollution and energy consumption, but as if the expectations regarding the role of information technology are excessive, as the use of modern technologies is certainly the main element in the construction of an smart city, but the human contribution must also be forgotten in order to realize the intelligent actions in the everyday lives of the people who live, study, work in the city or visit the city for one or several days for work or tourism. It is definitely necessary to discuss in parallel the development of the smart city with the improvement of education, as man, modern technologies and building a strategic vision for development are the main components in the implementation of a plan for the construction of a smart city. A smart city is a well-developed city, which is the result of combining several aspects, not only technical but also human, based on independent and independent citizens. The main assessment indicators should address both the social and human capital presented by the level of education development, the general level of the acquired qualification of the local population and, of course, the perception of the concept of lifelong learning, which should include the participation of citizens in public life in decision-making on the planning and development of the territory they inhabit. 


\section{MAIN ASPECTS, WHICH CHARACTERIZING THE SMART CITY.}

In general, three key elements characterizing the development of the smart city can be presented, the first one being the achievement of efficiency, which means improving the city's ability to provide effective public and private services to both citizens and companies, non-profit organizations purpose. The second element is related to environmental considerations, which should take into account the growing impact that large cities have on the quality of the environment in heavily populated urban areas. One of the main goals in this context for smart cities is to prevent further environmental degradation by reducing energy consumption, limiting air and water pollution. The third element is based on the use of innovation, which means that a smart city must use all new and available technologies to improve the quality of its core components, provide better services and reduce its environmental impact due to which technology is perceived as a key element in the creation of a smart city.

When linking regional policy to the development of smart cities, attention must also be paid to demographic dimensions of migration processes. Particular attention should be paid to the demographic factor in the shaping of social and economic development programs and the implementation of regional economic and social policies. [6] The demographic dimensions of migratory processes are based on the economic, social and historical characteristics of migration. The specific manifestations of the spatial movement of the population and their cross-border mobility are highlighted in the contemporary reality, with the possibility to be considered as neutralizing migratory movements, i.e. migration processes need to be evaluated in the context of system analysis as complex systems influenced by the level of development.

Migrations have an economic, political and demographic character and are determined by the individual's personal interests. The causes, directions and size of migrations are historically conditioned and develop within certain limits. Their forms and manifestations have a historical character. The change in political, social and economic conditions causes some forms of migration to disappear, and some forms adapt to them. Unemployment among immigrants no doubt has negative consequences as it raises social problems and threatens the internal security of each host country. The recent waves of emigration are predominantly formed by young and educated people, which exacerbates the deterioration of the fertile demographic contingent and the quality of human capital in the country. On the other hand, the immigration flow is largely formed by poorly qualified staff. Migration monitoring must be tailored to the expected demographic effects. There must be support for introducing an immigration policy based on an integrated approach to controlling, managing and anticipating migration processes.[7] As the social and economic development of our country, migratory processes that directly affect the existence of an underdeveloped population are important, which will in the future affect the imposition and implementation of policies for improvement of the pension insurance system. On the other hand, with the continuing aging trend of the population, we will also have a change in the structure of the workforce, by increasing the share of older workers, where labor change, education and health will also need to be changed. At some point, some of the employers will have to adapt jobs to the needs of the older workforce, and more flexible labor conditions on the labor market will have to be promoted. With the increase in the share of older workers, the state will need to make further efforts to realize modern and effective healthcare. In addition, the necessary social and medical services for the elderly will have to be provided, and as we know older people (and children) in terms of their physiology and chronic illnesses, they have a high need for medical care, 
and this will has led to an increase in public health spending and a further increase in the social security burden for workers. With regional aging, we will see a change in the provision of public services to the population in each separate territorial unit. The trend of increasing demand for health services and long-term care is observed after the age of 65. Research shows that this trend continues to about 75 years, and then there is a decline in demand [8]. It is precisely in relation to the rational reception of the negative demographic transformations of the societies of the European Union that the essential key will be the speed and the skills of each of the European countries to apply an integrated approach while mobilizing their economic, human, administrative and financial resources to develop and implementation of related policies. [9]

\section{CONCLUSION}

The construction of a smart city should provide the opportunity to solve the many public problems that arise through the implementation of solutions that are based on the latest technologies and are at the same time the product of the established partnerships between citizens, academic organizations, businesses, municipalities and the state administration i.e. between all interested parties. Normally, for the construction of an smart city it is necessary to consider it in the following six areas, namely economic development, mobility, environment, lifestyle, people and urban governance. Naturally, one of the most important elements is investment in people, which is why significant efforts should be made by state institutions to provide opportunities for qualifications and re-qualification of the population, especially in backward areas, where „unfortunately, the collaboration between the educational institutions and the private sector is far from satisfactory. The appropriate link between theory and practice has not been established yet. Many employers are not satisfied with the practical skills that the graduates have. It is especially important to increase investment in human capital with the state employers, local authorities and regional communities sharing the burden without ruling out individual responsibility. Concrete tools for implementing the policy of continuing vocational training and life-long learning could be: the establishment of sectoral funds for improving the qualification of the employed and setting up individual training accounts [10]". In a constantly globalizing and dynamically changing world, with intensive ongoing integration processes for the socio-economic development of individual regions, it is necessary to increase foreign direct investment, which can be achieved by creating better conditions for attracting international companies And on the other hand by improving the administrative service of the population and the business. This will create a practical opportunity to attract "multinational companies doing business in different regions of the world", thus being able to "prevent the risk of doing business in just one geographic market" [11]. Managing multinational companies has "different company structures production structures, geographic structure and functional structure," with most "multinational companies having a geographic organizational structure at their disposal," which means working with people from "different cultures, religions and Economies ", which, on the other hand, affects companies as a" development-inhibiting effect "[11]. Naturally, international companies are interested in the "spatial behavior of their clients," and the effective international manager must carefully "recognize and assess the potential differences in culture, economy, politics and ideology," as a common problem is "not understanding the individual Culture, language and ethnic characteristics and peculiarities of the population of the countries in the world ", and here, very often from the point of view of economic subjects, arises the question of the understanding of the" different 
culture As an opportunity for the establishment of good business relations "[11]. This also requires attention to risk management, which can be seen as a "common process of undertaking the necessary steps to build a secure network in a production environment, providing specific policies and procedures that outline the basic needs and expectations Network security of the corporate structure of the organization "[12]. Scientificallypractical interest will be the on going discussion on the topic of achieving greater efficiency and effectiveness of the different forms of interregional cooperation, whether it is the result of voluntary cooperative or compulsory interregional co-operation. The provision, or rather delegation of functions to joint interregional structures is supported by a variety of financial packages (mainly transfers and subsidies), but the lack of financial capacity places these structures in a dependent position vis-à-vis the central government. The only exceptions in the European context are in France and some German provinces where interregional structures have legally regulated systems for generating their own revenues through taxation, allowing them to have relative autonomy in implementing integration policies for local communities inhabiting the territorial structures of the interregional organization [13].

\section{REFERENCES}

[1] „State of European Cities Report”, European Commission 2010;

[2] „8th Progress Report on Economic, Social and Territorial Cohesion“, European Commission 2013

[3] Communication from the commission to the European parliament, the council, the European economic and social committee and the committee of the regions the urban dimension of EU policies - Key features of an EU urban agenda /COM/2014/0490 final/ available to https://eurlex.europa.eu/legal-content/EN/TXT/?uri=CELEX:52014DC0490 on 10.03.2019.

[4] Williams, B., Walsh, C., Boyle, I., The development of the functional urban region of Dublin: Implications for regional development markets and planning, 2005, p. 9

[5] Spatial planning: Key instrument for development and effective governance with special reference to countries in transition, United Nations, New York and Geneva, 2008

[6] Naydenov, Kl., Influence of the demographic factor on the regional social and economic development", SGEM 2017, Volume I, p.363 - 369,ISBN 978-619-7408-23-2 [7] Ivanov, M., Naydenov, Kl., Migration and demographic challenges for Bulgaria, 5th SGEM International Multidisciplinary Scientific Conferences on SOCIAL SCIENCES and ARTS SGEM2018, 2018, doi:10.5593/sgemsocial2018/4.1/S18.045

[8] Naydenov, Kl., Traykov, T., Aging population in Bulgaria - trends, peculiarities and regional differences, Scientific Conference of BGS, Varshets, 2016, Bulgaria, available to http://geography.bg/images/dokladi/38.pdf on 10.03.2019

[9] Naydenov, Kl., Ivanov, M., Regional peculiarities in the transfer of tools influencing the national and regional policy of the country, Transnational transfer of administrative models and instrument: possibilities, constraints and risk, proceedings of First International Conference on Public Administration Sofia University "St. Kliment Ohridski", April 2017, Sofia available to https://www.ceeol.com/search/book-detail?id=649272 on 10.03.2019

[10] Naydenov Kl., Education and employment in South East Europe, 13th International scientific conference „The teacher of the future“, Budva, Montenegro, 25-28 may 2017

[11] Naydenov Kl. - Multinational Companies Managers And Geography - How To Understand Different Cultures, AAG Annual Meeting 2010, Washington, USA 
[12] Naydenov, Kl. - "Methodology for global change vulnerability assessments", First International Conference "Human Dimensions of Global Change In Bulgaria", 22 - 24 April 2004, Sofia, Bulgaria

[13] Ivanov, M., Integration models for interregional cooperation, Knowledge international journal, vol. 17.2, Skopje, 2017 